\section{Don't glorify Arab astronomy}

The substantial achievements in astronomy that Nidhal Guessoum refers to occurred earlier than the 'golden age' of Arab astronomy from the ninth to the sixteenth century AD (Nature 498, 161-164; 2013).

Astronomy developed between the fourth century вс and the first century $\mathrm{AD}$, but especially in the third century вС. It matured from tables of observations, from which only a few general patterns were recognized (the saros eclipse cycles, for example), into a sound understanding of the Solar System. This included good estimates for the size of Earth and the sizes of the Sun and the Moon, as well as their distances, and the discovery of the precession of the equinoxes. More importantly, a majestic mathematical construction allowed the prediction of the positions of all of the major bodies visible in the sky, with a precision close to the best available with observation (10 minutes of arc). These achievements were products of Alexandrian astronomy, mostly by Greeks living in Egypt, and were summarized by the writer Claudius Ptolemy.

Good intentions motivate Guessoum's examples of Arab excellence in astronomy, such as columns (gnomons) that were used to measure time (common in the earlier, scientifically illiterate Roman Empire) and of sailors using the arc of the Moon to indicate the east-west line (a technique already known for a couple of millennia). But glorifying these as achievements shows a lack of respect for today's students in the Arab world. Furthermore, the stated strictly religious motivations of Arab astronomy, absent in Alexandrian times, may sound like a justification for religious control of science - still a danger in many countries.

To their credit, Arab astronomers recognized the value of Alexandrian astronomy, and even developed it in some details. They saved the old astronomy, which, through Nicolaus Copernicus, led to the ignition of modern science. Carlo Rovelli Aix-Marseille University, Marseille, France. rovelli@cpt.univ-mrs.fr

\section{Shale gas: pollution fears in China}

The confirmation of groundwater contamination owing to shale-gas extraction in the United States (see Nature 498, 415-416; 2013) should be a wake-up call for China too. With Chinese groundwater resources deteriorating fast and shale-gas exploitation mushrooming, careful drilling operations and continuous monitoring are needed.

China has the world's largest shale-gas reserves. To satisfy growing energy demands and to reduce carbon emissions, China has prioritized 13 provinces for shale-gas exploitation. Four of these are in northern and northwestern China, where groundwater provides about 70\% of drinking water. Around 90\% of China's shallow groundwater is already polluted, and $37 \%$ cannot be treated for use as drinking water (J. Qiu Science 334, 745; 2011).

Crops irrigated by polluted groundwater have been contaminated. For example, $36 \%$ of rice grown in Hunan province, one of the 13 shalegas priority areas, was found to have cadmium levels above those specified by China's food standards regulation (M. Lei et al. Acta Sci. Circumst. 11, 23142320; 2010; in Chinese).

Oil-and-gas exploitation has already exacerbated groundwater pollution, and in Henan, another priority province, $81 \%$ and $29 \%$ of shallow groundwater resources have been contaminated by volatile phenol and cyanide, respectively (Y. M. Wang and J. F. Dang
J. Geol. Hazard. Environ. Pres. 11, 271-273; 2000; in Chinese). Compared to those in the United States, Chinese shale-gas extraction operations are poorly developed. The chances of poor well construction and hence of contamination are higher, and monitoring programmes are largely absent. Energy and water are bottlenecks that will affect China's sustainable development; better coordination between the two sectors is desperately needed. Hong Yang University of Southampton, UK. hongyanghy@gmail.com Roger J. Flower, Julian R. Thompson University College London, UK.

\section{Shale gas: surface water also at risk}

Researchers are focusing on the effects of shale-gas development on groundwater quality (see Nature 498, 415-416; 2013). Surface-water contamination is also a risk.

Rivers and streams near shale-gas extraction sites are threatened. Reduced streamflow causes sediment to accumulate, and released wastewater contains chemical additives, organic matter, metals, radioactive materials, nutrients and dissolved solids (S. Entrekin et al. Front. Ecol. Environ. 9, 503-511;2011). Each gas well needs between 7.5 million and 26 million litres of water a day. Resulting water shortages can affect aquatic habitat and agricultural production, and waste treatment can raise the concentration of pollutants such as chloride or total suspended solids in nearby surface waters (S. M. Olmstead et al. Proc. Natl Acad. Sci. USA 110, 4962-4967; 2013).

More data must be collected on the risks of shale-gas extraction to surface-water quality, to support contaminant monitoring and removal.

Guangming Zeng, Ming Chen Hunan University, Changsha, China. zgming@hnu.edu.cn Zhuotong Zeng Central South University, Changsha, China.

\section{Badger-cull statistics carry uncertainty}

Scientists have spoken out for and against the 'evidencebased' policy for badger culling in England for the control of cattle tuberculosis (TB) (see M. Woolhouse and J. Wood, Nature 498, 434; 2013 and go.nature.com/nem9ua). Each faction emphasizes different statistics from the Randomised Badger Culling Trial (RBCT) on the impact of culling.

Appreciable uncertainty surrounds Woolhouse and Wood's statement that widespread badger culls "roughly halved" the incidence of cattle TB. This $54 \%$ reduction occurred inside culling areas only after five years of annual culls, and the benefits diminished after just 18 months (95\% confidence interval: 38-66\%; H. E. Jenkins et al. Int. J. Infect. Dis. 12, 457-465; 2008). In my view, this maximal risk reduction is relevant in setting stakeholder and policy-maker expectations for culling only if it can be sustained beyond 18 months (H. E. Jenkins et al. PLoS ONE 5, e9090; 2010).

'On-off culling', in which annual widespread culling resumes when cattle $\mathrm{TB}$ rates increase, might in principle sustain such a risk reduction, but the RBCT did not test this approach. Careful epidemiological and ecological modelling and cost analysis would be required to predict the impacts of on-off culling. It might trigger the reappearance of the transient increases in TB that were observed early in the RBCT outside culling areas, attributed to increased badger movements. Christl Donnelly Imperial College London, UK. c.donnelly@imperial.ac.uk Competing financial interests declared. See http://dx.doi. org/10.1038/499154d. 